\title{
Are Cycling and Walking Good for All? Tracking Differences in Associations among Active Travel, Socioeconomics, Gentrification, and Self-reported Health
}

\author{
Jesus M. Barajas \\ University of California, Davis \\ Lindsay M. Braun \\ University of Illinois at Urbana-Champaign
}

\begin{abstract}
While the health benefits of cycling and walking have been well established, questions remain about whether these benefits hold in varying socioeconomic contexts, including across demographic groups and in the context of neighborhood change. This study examines this relationship, identifying associations between cycling or walking and self-reported health, whether socioeconomic status moderates these associations, and whether gentrification influences the potential moderating effects. This study uses the 2017 National Household Travel Survey, subset to adults who lived in central cities $(n=88,698)$. Weighted ordered logistic regression models were fit to estimate self-reported health status separately for cycling and walking. Gentrification was measured using an indicator based on previous research using US Census data. People who had cycled in the past week and each additional walking trip were associated with higher odds of reporting better health. Socioeconomic status moderated the positive associations between active transportation and health in a few key cases. Cycling was not as strongly associated with health for Black cyclists or employed cyclists, while women had smaller benefits from each additional walking trip compared to men. Gentrification was an insignificant moderating factor in most cases. Findings suggest planning efforts that continue to support programs that promote cycling and walking are crucial tools in the public health toolbox. The health gains from active transportation might be experienced in a variety of neighborhood contexts. Nevertheless, infrastructure investments and policy must be attentive to inequities across neighborhoods.
\end{abstract}

Keywords: bicycling, walking, gentrification, self-reported health, equity 


\section{Introduction}

A large body of evidence finds that walking and cycling for transportation are positively associated with health. Walking and cycling are beneficial not only in terms of physical activity and obesity (Pucher et al., 2010a; Wanner et al., 2012), but also for downstream health outcomes such as cardiovascular disease, type 2 diabetes, inflammatory markers, and all-cause mortality (Andersen et al., 2000; Dinu et al., 2019; Matthews et al., 2007; Saunders et al., 2013; Smith et al., 2019). This evidence has elevated the role of active modes in transportation planning, encouraging greater investment in infrastructure such as sidewalks and bike lanes, and in broader built environment patterns that support walking and cycling in daily travel (Alliance for Biking \& Walking, 2016; Pucher et al., 2010b).

While the health benefits of walking and cycling have been well established, questions remain about whether these benefits hold in varying socioeconomic contexts. There are several reasons to expect that people of color and those with lower socioeconomic status (SES) in the U.S. might not experience the full health benefits that research suggests walking and cycling can

provide. First, while much of the literature on transportation and health focuses on the benefits of walking and cycling, these modes are also associated with health risks related to pollution exposure and injury. In the case of cycling, several studies have suggested that these pollution and injury risks are outweighed by the physical activity benefits (Mueller et al., 2015; RojasRueda et al., 2016; Tainio et al., 2016). However, these studies have generally not considered spatial variations in risk that might arise from differing infrastructure conditions like traffic volumes or infrastructure quality. Given evidence that people of color and low SES have disproportionately low access to active transportation infrastructure (Braun et al., 2019; Smith et al., 2017) and tend to live closer to major roadways (Hajat et al., 2015), they may be particularly vulnerable to the risks of active transportation and their net health benefits may be correspondingly lower.

Second, emerging evidence points to potential associations between active transportation infrastructure investment and gentrification, which could mean that people of color and low SES are ultimately excluded from the types of environments that support walking and cycling. These associations likely stem in part from the value placed on "walkability" and "bikeability" as urban amenities that are capitalized into land values (Bartholomew and Ewing, 2011; Li and Joh, 2017) and the framing of active transportation investment as an economic development strategy for cities (Hoffmann and Lugo, 2014). In the case of walking, recent studies have found that greater walkability is associated with increasing housing values (Knight et al., 2018), lower housing affordability for renters and low-income households (Bereitschaft, 2019; Quastel et al., 2012), and other cultural markers of gentrification (Quastel et al., 2012), and that walkability tends to be clustered in stable and gentrifying neighborhoods (Knight et al., 2018). Walkability measures have even been used in San Francisco as part of an "early warning system" to identify neighborhoods at risk of gentrification (Chapple and Zuk, 2016). In the case of cycling, research has found that property values are higher in proximity to bike trails and paths (Krizek and Johnson, 2006; Welch et al., 2016) and that other cycling investments such as bike lanes and bicycle sharing programs are associated with increasing property values and other measures of gentrification over time (Flanagan et al., 2016; Hirsch et al., 2017; Immergluck and Balan, 2018; Pelechrinis et al., 2017).

The causal direction of these associations is a subject of much debate, as is the definition of gentrification and whether it is inherently problematic if it does not lead to displacement of existing residents (Zuk et al., 2018). If the gentrification trends associated with walking and 
cycling interventions do lead to displacement, people of color and low SES will be less likely to benefit from them and thus less likely to experience the health benefits of walking and cycling more broadly. Even in the absence of displacement, however, gentrification can still lead to exclusion from active transportation. Indeed, processes for creating "walkable" and "bikeable" spaces - particularly in gentrifying areas - are often exclusionary. This is especially evident in the case of cycling, as bicycle planning and advocacy tend to be dominated by white, male, and middle- to upper-class actors and interests (Golub, 2016). The impacts of these processes and the threat of gentrification can be seen in recent bike lane and trail projects in cities such as Chicago, Portland, and Washington, D.C., where residents of historically marginalized but gentrifying neighborhoods have pushed back against cycling interventions viewed as imposed upon them by cities and by wealthier, white newcomers (Benesh, 2015; Freed, 2015; Greenfield, 2012;

Herrington and Dann, 2016; Lubitow et al., 2016). Exclusionary planning practices may work to exclude historically marginalized groups from the health benefits of walking and cycling, or minimize their effects.

A final possibility lies in the distribution of active travel behavior and health status by socioeconomic characteristics. This possibility is best illustrated through the case of walking, which tends to be more common among low-income households. In 2017, 61 percent of households earning less than $\$ 10,000$ per year reported walking for travel at least a few times per week, compared to 39 percent of all other households (U.S. Department of Transportation, Federal Highway Administration, 2017). Similarly, between 2014 and 2018 mode shares of walking to work were slightly higher for Black and Hispanic workers (2.7 and 2.9 percent, respectively) compared to white workers ( 2.5 percent); workers earning less than $\$ 25,000$ per year made up the majority of pedestrian commuters (57 percent); and the median income of those walking to work was the lowest of all commute modes $(\$ 20,645$ compared to $\$ 36,976$ for all workers) (U.S. Census Bureau, 2018). Given that people of color and low SES also tend to have a disproportionately high burden of chronic disease (August and Sorkin, 2011), it is possible that the physical activity gains from active transportation are insufficient to overcome the substantial health disparities already faced by these populations.

These factors suggest that the health benefits of walking and cycling may not be universal, and in fact may be unevenly distributed across socioeconomic groups, complicating the approach of creating walkable and bikeable communities. We examined these relationships in this study, asking three related research questions about cycling and walking and health:

- What is the association between cycling or walking and self-reported health?

- Does socioeconomic status moderate the association between cycling or walking and health?

- Does gentrification influence the moderating effects?

We tested these three research questions using the conceptual framework in Figure 1. First, we separately examined whether cycling and walking were associated with self-reported health, controlling for the built environment and socioeconomic characteristics (arrow 1). Then, we assessed whether these associations between cycling or walking and self-reported health differed by - that is, were moderated by - socioeconomic characteristics related to race, ethnicity, and SES (arrow 2). Finally, we tested whether the moderating effects of socioeconomic characteristics, in turn, differed by gentrification status (arrow 3 ). 


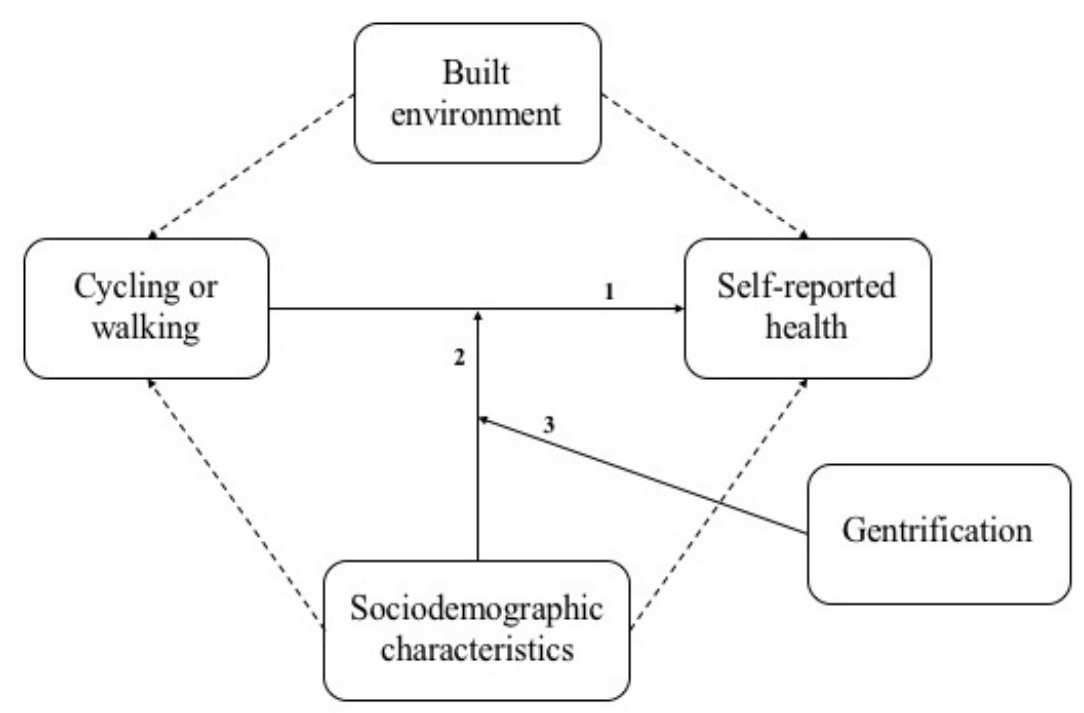

FIGURE 1 Conceptual framework of expected associations between active transportation, health, socioeconomic characteristics, and gentrification

\section{Data and methods}

\subsection{Data}

We used the 2017 National Household Travel Survey (NHTS) for data on travel and selfreported health. The NHTS is a nationally representative survey administered about every eight years in the United States in which respondents report a full day of travel for all household members. We used a confidential version of the dataset that provided census tract identifiers to allow for measurement of neighborhood-level factors.

For the first time, the 2017 NHTS asked a question about self-reported health, "Would you say that in general your health is...?", offering a five-point response scale from poor to excellent. This measure of self-reported health was the key dependent variable in the statistical models, which are described in more detail in the next section. Key explanatory variables from the NHTS included the number of trips for which a respondent bicycled and walked for transportation in the previous seven days, recomputed by subtracting the number of trips made solely for exercise from the total number of bicycle and walk trips made. Socioeconomic variables were also taken from the NHTS, including race and ethnicity, household income quintile, educational attainment, employment status, age, gender, and immigrant status. Population density was taken from the American Community Survey (ACS). Continuous variables were standardized to aid with model fitting.

To consider the dynamics of neighborhood change, we identified gentrifying tracts from ACS data using a definition from Freeman (2005). The period over which we examined gentrification was 2006 to 2017, using the five-year ACS data from 2006-2010 and 2013-2017. Other gentrification measures applied to a nationwide context exist (e.g. Landis, 2016), and such measures have been criticized for focusing on the outcome of gentrification to the exclusion of process, such as increasing public investment in disinvested neighborhoods (Zuk et al., 2018). Nevertheless, we used the Freeman definition because consistent data were available nationwide, it relied on multiple socioeconomic indicators, and has been commonly used in whole or in part 
in other studies on gentrification (Bardaka et al., 2018; e.g. Flanagan et al., 2016). A census tract was defined as gentrifying if it was located in the central city, had a median income lower than the metropolitan area at the beginning of the study period, had a lower proportion of new housing compared to the metropolitan area, had an increase in educational attainment greater than the metropolitan area, and had an increase in real housing prices. This definition captures census tracts that have recently begun gentrifying or have recently accelerated gentrification while also allowing the use of stable census tract boundaries between the two survey periods.

We restricted the data sample to adults aged 18 or older living in central cities; that is, those in census tracts eligible to gentrify per the definition above.

\subsection{Methods}

We examined associations between cycling or walking and self-reported health, and whether those associations were moderated by SES and by living in a gentrifying neighborhood, using a series of ordered logistic regression models. Ordered logistic regression models estimate the (logit of) the probability that an outcome $Y$ is less than or equal to a specific category $j$ (Christensen, 2020). The dependent variable for each model was the five-point self-reported health scale. We fit separate models for cycling and walking as explanatory variables. In the cycling models, the main independent variable was a binary indicator of whether the respondent cycled for transportation ${ }^{1}$ in the previous seven days. Although the NHTS provided data on trip frequency, only $6 \%$ of respondents had cycled at all, so we dichotomized the variable to increase statistical power. In the walking models, the main independent variable was the number of trips walked for transportation in the previous seven days. In each subsequent model, we stepped in control variables and interactions to help answer each of the three research questions. Models were weighted using replicate survey weights to account for oversampling in certain states and for non-response bias in certain demographic groups.

Because associations between active travel, socioeconomic status, and gentrification could look different in different places, we also fit the same set of models as multilevel models with varying intercepts for core-based statistical areas. Likelihood ratio tests indicated that the multilevel models were not significant improvements over the single-level models, so we do not report those results. In other words, the associations tested in the models did not vary by metropolitan area.

\section{Results}

\subsection{Descriptive statistics}

The associations between self-reported health and most analysis categories matched expectations (descriptive statistics are shown in Table 1). A substantial majority of the sample reported being in good health or better (90\%), with 32\% reporting being in excellent health. Cycling was more common among higher health statuses: around $2 \%$ of people in poor health cycled for transportation, while $11 \%$ of people in excellent health did. Walking for transportation was more common, and people in better health walked more than those in poorer health.

Socioeconomic status was correlated with health status; people of color, lower-income people, and people with lower educational attainment were more likely to report being in poor health. Being employed was associated with better health, while women made up a declining

\footnotetext{
${ }^{1}$ The NHTS dataset did not directly report the frequency of cycling or walking for transportation. We constructed the variables by subtracting the number of trips made for exercise from the total number of trips made.
} 
share of the sample in each category as health status increased. People in better health tended to be younger. Immigrants made up the same proportion of the sample regardless of health status.

A small share of the sample lived in gentrifying tracts (7\%). There was no statistically significant relationship between health status and gentrification. We also examined differences in active travel behavior across gentrification status of the census tract, not shown in Table 1. A greater proportion of cyclists (10\%) lived in gentrified tracts compared to non-gentrified tracts (7\%). Likewise, on average, people in gentrified census tracts walked more frequently (5.8 trips) than those in non-gentrified tracts (3.8 trips). Both differences were statistically significant. 
TABLE 1 Weighted characteristics of NHTS sample, overall and by self-reported health status

\begin{tabular}{|c|c|c|c|c|c|c|c|}
\hline & $\begin{array}{c}\text { Overall, } \\
N= \\
|0449|\end{array}$ & $\begin{array}{c}\text { Poor, } \\
\mathrm{N}=2388 \\
(2.4 \%)^{\prime}\end{array}$ & $\begin{array}{c}\text { Fair, } \\
\mathrm{N}=8765 \\
(8.2 \%)^{\prime}\end{array}$ & $\begin{array}{c}\text { Good, } \\
N=25472 \\
(24 \%)^{\prime}\end{array}$ & $\begin{array}{c}\text { Very good, } \\
\mathrm{N}=36973 \\
(34 \%)^{1}\end{array}$ & $\begin{array}{c}\text { Excellent, } \\
\begin{array}{c}\mathrm{N}=30893 \\
(32 \%)^{1}\end{array}\end{array}$ & $\begin{array}{c}\text { p- } \\
\text { value }^{2}\end{array}$ \\
\hline $\begin{array}{l}\text { Cycled for } \\
\text { transportation in } \\
\text { previous week (\% } \\
\text { yes) }\end{array}$ & $6.9 \%$ & $2.2 \%$ & $3.1 \%$ & $3.8 \%$ & $6.6 \%$ & $11 \%$ & $<0.001$ \\
\hline $\begin{array}{l}\text { Walking trips for } \\
\text { transportation in } \\
\text { previous week (\#) }\end{array}$ & $3.9(7.9)$ & $2.5(6.8)$ & $3.0(6.9)$ & $3.5(7.5)$ & $4.1(8.2)$ & $4.4(8.3)$ & $<0.001$ \\
\hline $\begin{array}{l}\text { Lives in gentrifying } \\
\text { tract (\% yes) }\end{array}$ & $7.3 \%$ & $6.5 \%$ & $8.0 \%$ & $7.6 \%$ & $6.8 \%$ & $7.5 \%$ & 0.210 \\
\hline $\begin{array}{l}\text { Population density } \\
\left(\mathrm{km}^{2}\right)\end{array}$ & $\begin{array}{c}3,852 \\
(7,736)\end{array}$ & $\begin{array}{c}3,593 \\
(6,563)\end{array}$ & $\begin{array}{l}3,990 \\
(7,7 \mid 4)\end{array}$ & $\begin{array}{l}3,708 \\
(7,289)\end{array}$ & $3,836(7,972)$ & $\begin{array}{l}3,960 \\
(7,887)\end{array}$ & 0.164 \\
\hline Race/ethnicity & & & & & & & $<0.001$ \\
\hline White & $54 \%$ & $40 \%$ & $39 \%$ & $50 \%$ & $58 \%$ & $57 \%$ & \\
\hline $\begin{array}{l}\text { Black or African } \\
\text { American }\end{array}$ & $16 \%$ & $29 \%$ & $27 \%$ & $18 \%$ & $14 \%$ & $14 \%$ & \\
\hline Hispanic/Latino & $20 \%$ & $23 \%$ & $24 \%$ & $22 \%$ & $18 \%$ & $19 \%$ & \\
\hline Asian & $5.7 \%$ & $2.7 \%$ & $3.7 \%$ & $5.6 \%$ & $6.3 \%$ & $6.0 \%$ & \\
\hline Other & $4.4 \%$ & $4.2 \%$ & $5.4 \%$ & $4.8 \%$ & $4.1 \%$ & $4.2 \%$ & \\
\hline $\begin{array}{l}\text { Household income } \\
\text { (quintiles) }\end{array}$ & & & & & & & $<0.001$ \\
\hline Less than $\$ 25,000$ & $24 \%$ & $58 \%$ & $49 \%$ & $30 \%$ & $18 \%$ & $18 \%$ & \\
\hline$\$ 25,000$ to $\$ 49,999$ & $22 \%$ & $23 \%$ & $24 \%$ & $25 \%$ & $23 \%$ & $18 \%$ & \\
\hline$\$ 50,000$ to $\$ 74,999$ & $16 \%$ & $7.2 \%$ & $12 \%$ & $16 \%$ & $17 \%$ & $15 \%$ & \\
\hline$\$ 75,000$ to $\$ 124,999$ & $21 \%$ & $7.6 \%$ & $11 \%$ & $18 \%$ & $24 \%$ & $24 \%$ & \\
\hline$\$ 125,000$ or more & $17 \%$ & $3.6 \%$ & $4.5 \%$ & $10 \%$ & $18 \%$ & $25 \%$ & \\
\hline $\begin{array}{l}\text { Educational } \\
\text { attainment }\end{array}$ & & & & & & & $<0.001$ \\
\hline Less than high school & $12 \%$ & $25 \%$ & $18 \%$ & $11 \%$ & $7.6 \%$ & $14 \%$ & \\
\hline High school & $48 \%$ & $58 \%$ & $63 \%$ & $57 \%$ & $45 \%$ & $37 \%$ & \\
\hline College degree & $40 \%$ & $17 \%$ & $19 \%$ & $32 \%$ & $48 \%$ & $49 \%$ & \\
\hline Employed & $62 \%$ & $11 \%$ & $32 \%$ & $58 \%$ & $70 \%$ & $71 \%$ & $<0.001$ \\
\hline Immigrant & $16 \%$ & $19 \%$ & $17 \%$ & $17 \%$ & $16 \%$ & $14 \%$ & 0.005 \\
\hline Age & $40(21)$ & $60(17)$ & $54(18)$ & $46(20)$ & $39(20)$ & $30(19)$ & $<0.001$ \\
\hline Female & $51 \%$ & $53 \%$ & $58 \%$ & $52 \%$ & $52 \%$ & $49 \%$ & $<0.001$ \\
\hline
\end{tabular}

'Statistics presented: \%; mean (SD)

${ }^{2}$ Statistical tests performed: chi-square test of independence; Wald test 


\subsection{Bicycling models}

The descriptive statistics in Table 1 indicated that cycling for transportation was positively associated with self-reported health status before adjusting for other covariates. This relationship held after adjustment for socioeconomic status and census tract population density (Table 2, model B1). All else equal, cyclists had odds of reporting better health 1.5 times that of noncyclists $(95 \% \mathrm{CI}=[1.28,1.66])$. Socioeconomic characteristics generally had the expected direction of association. Compared to white people, people of color were less likely to report higher health status. Better health was associated with higher levels of household income. For example, people in the second quintile of household income $(\$ 25,000-\$ 49,999)$ had odds of reporting better health 1.4 times higher than those in the lowest income quintile, while those in the highest income quintile ( $\$ 125,000$ or more) had 3.3 times the odds of reporting better health. Higher educational attainment was associated with better health, as was employment status and younger age. Immigrants were more likely to report better health compared to people born in the United States. Population density was not significantly associated with self-reported health.

Model B2 examined the potential moderating effects of socioeconomic status by interacting all the socioeconomic variables with the cycling indicator. The main effect of cycling became insignificant. While the main socioeconomic variables remained significant, only a few of the interacted variables - including Black or African American race, employment status, and age - were significant. We interpret this to mean that socioeconomic status moderates the health effect of cycling in a few key cases. For example, holding all other variables at their reference values, Black cyclists had 0.63 times the odds of reporting a higher health status compared to white non-cyclists. The odds ratio was slightly lower than for Black non-cyclists, who had 0.76 times the odds of reporting better health compared to white non-cyclists. But comparing white and Black cyclists, the difference was even greater: Black cyclists had less than half the odds of reporting better health compared to white cyclists. Employed cyclists reported better health than unemployed cyclists, though not as great as the difference between employed non-cyclists and unemployed non-cyclists. Older adults were less likely to report better health compared to younger adults, but differences in the odds of higher health status between cyclists and noncyclists increased with age.

Finally, in model B3 we tested whether living in a gentrifying tract changed the relationships we found in model B2 by adding interaction terms with gentrification status. Neither the main effects of gentrification, the two-way interaction terms with socioeconomic characteristics, nor the three-way interaction terms with cycling and socioeconomic status were statistically significant. 
TABLE 2 Associations between cycling for transportation and self-reported health

\begin{tabular}{|c|c|c|c|}
\hline & BI & B2 & B3 \\
\hline Cycled for transp. in prev. week & $\begin{array}{c}1.460 * * * \\
(1.280,1.664)\end{array}$ & $\begin{array}{c}1.618 \\
(0.729,3.590)\end{array}$ & $\begin{array}{c}1.608 \\
(0.639,4.045)\end{array}$ \\
\hline Gentrified tract & & & $\begin{array}{c}1.105 \\
(0.595,2.050)\end{array}$ \\
\hline \multicolumn{4}{|l|}{ Race } \\
\hline Black or African American & $\begin{array}{c}0.750 * * * \\
(0.639,0.880)\end{array}$ & $\begin{array}{c}0.764 * * \\
(0.646,0.902)\end{array}$ & $\begin{array}{c}0.755 * * \\
(0.636,0.896)\end{array}$ \\
\hline Hispanic/Latino & $\begin{array}{c}0.821 * * * \\
(0.738,0.914)\end{array}$ & $\begin{array}{c}0.83 I * * \\
(0.74 I, 0.93 I)\end{array}$ & $\begin{array}{c}0.835 * * \\
(0.740,0.942)\end{array}$ \\
\hline Asian & $\begin{array}{c}0.767 * * \\
(0.637,0.923)\end{array}$ & $\begin{array}{c}0.783 * \\
(0.643,0.954)\end{array}$ & $\begin{array}{c}0.788 * \\
(0.640,0.970)\end{array}$ \\
\hline Other & $\begin{array}{c}0.711 \text { *** } \\
(0.590,0.857)\end{array}$ & $\begin{array}{c}0.712 * * * \\
(0.592,0.858)\end{array}$ & $\begin{array}{c}0.679 * * * \\
(0.590,0.782)\end{array}$ \\
\hline \multicolumn{4}{|l|}{ Household income (quintiles) } \\
\hline$\$ 25,000$ to $\$ 49,999$ & $\begin{array}{c}1.446 * * * \\
(1.258,1.662)\end{array}$ & $\begin{array}{c}1.477 \text { *** } \\
(1.294,1.686)\end{array}$ & $\begin{array}{c}1.477 \text { *** } \\
(1.244,1.753)\end{array}$ \\
\hline$\$ 50,000$ to $\$ 74,999$ & $\begin{array}{c}1.938 * * * \\
(1.669,2.25 \mathrm{I})\end{array}$ & $\begin{array}{c}1.931 * * * \\
(1.677,2.222)\end{array}$ & $\begin{array}{c}1.904 * * * \\
(1.654,2.193)\end{array}$ \\
\hline$\$ 75,000$ to $\$ 124,999$ & $\begin{array}{c}2.265 * * * \\
(2.010,2.552)\end{array}$ & $\begin{array}{c}2.258 * * * \\
(2.013,2.534)\end{array}$ & $\begin{array}{c}2.281 * * * \\
(2.005,2.596)\end{array}$ \\
\hline$\$ 125,000$ or more & $\begin{array}{c}3.299 * * * \\
(2.927,3.719)\end{array}$ & $\begin{array}{c}3.323 * * * \\
(2.950,3.743)\end{array}$ & $\begin{array}{c}3.315 * * * \\
(2.877,3.820)\end{array}$ \\
\hline \multicolumn{4}{|l|}{ Educational attainment } \\
\hline High school & $\begin{array}{c}1.898 \text { *** } \\
(1.693,2.126)\end{array}$ & $\begin{array}{c}1.879 * * * \\
(1.657,2.132)\end{array}$ & $\begin{array}{c}1.901 * * * \\
(1.646,2.196)\end{array}$ \\
\hline College degree & $\begin{array}{c}3.013 * * * \\
(2.653,3.422)\end{array}$ & $\begin{array}{c}2.968 * * * \\
(2.590,3.40 \mathrm{I})\end{array}$ & $\begin{array}{c}2.992 * * * \\
(2.580,3.469)\end{array}$ \\
\hline Employed & $\begin{array}{c}1.657 * * * \\
(1.520,1.807)\end{array}$ & $\begin{array}{c}1.678 * * * \\
(1.519,1.855)\end{array}$ & $\begin{array}{c}1.669 * * * \\
(1.521,1.832)\end{array}$ \\
\hline Immigrant & $\begin{array}{c}1.212 * * * \\
(1.139,1.290)\end{array}$ & $\begin{array}{c}1.202 * * * \\
(1.132,1.278)\end{array}$ & $\begin{array}{c}1.204 * * * \\
(1.142,1.269)\end{array}$ \\
\hline Female & $\begin{array}{c}0.996 \\
(0.948,1.046)\end{array}$ & $\begin{array}{c}0.998 \\
(0.947,1.05 I)\end{array}$ & $\begin{array}{c}0.997 \\
(0.943,1.055)\end{array}$ \\
\hline Age (std.) & $\begin{array}{c}0.529 * * * \\
(0.508,0.55 \mathrm{I})\end{array}$ & $\begin{array}{c}0.525 \text { *** } \\
(0.505,0.546)\end{array}$ & $\begin{array}{c}0.524 * * * \\
(0.504,0.545)\end{array}$ \\
\hline Age $(\text { std. })^{2}$ & $\begin{array}{c}1.34 \mid * * * \\
(1.296,1.387)\end{array}$ & $\begin{array}{c}1.348 * * * \\
(1.302,1.395)\end{array}$ & $\begin{array}{c}1.359 * * * \\
(1.312,1.408)\end{array}$ \\
\hline Population density (std.) & $\begin{array}{c}1.006 \\
(0.991,1.022)\end{array}$ & $\begin{array}{c}1.005 \\
(0.990,1.021)\end{array}$ & $\begin{array}{c}1.009 \\
(0.991,1.028)\end{array}$ \\
\hline \multicolumn{4}{|l|}{ Interactions } \\
\hline $\begin{array}{l}\text { Cycling } \\
\text { Gentrification }\end{array}$ & $\begin{array}{l}\text { No } \\
\text { No }\end{array}$ & $\begin{array}{l}\text { Yes } \\
\text { No }\end{array}$ & $\begin{array}{l}\text { Yes } \\
\text { Yes }\end{array}$ \\
\hline Bike $\times$ Black or African American & & $\begin{array}{c}0.5 \mid 5 * * * \\
(0.37|, 0.7| 4)\end{array}$ & $\begin{array}{c}0.587 * * \\
(0.420,0.820)\end{array}$ \\
\hline Bike $\times$ Employed & & $\begin{array}{c}0.694 * \\
(0.499,0.965)\end{array}$ & $\begin{array}{c}0.765^{\wedge} \\
(0.567,1.032)\end{array}$ \\
\hline Bike $\times$ Age & & $1.215 * * *$ & $1.280 * *$ \\
\hline
\end{tabular}


$(1.106,1.335)$

$(1.097,1.494)$

\begin{tabular}{l}
$\mathrm{N}$ \\
\cline { 2 - 2 } $\mathrm{p}<0.001 ; * * \mathrm{p}<0.01 ; * \mathrm{p}<0.05 ;{ }^{\wedge} \mathrm{p}<0 . \mathrm{I}$. std. = standardized. Reference cases: Race $=$ White; Income \\
$=$ Less than $\$ 25,0 ;$ Education = Less than high school. Threshold values not shown.
\end{tabular}

\subsection{Walking models}

We used the same model specifications to examine associations between walking for transportation and self-reported health status. Overall, the walking models showed similar patterns to the cycling models, though the main effects of active transportation remained significant across all the models (Table 3 ). As for cycling, the descriptive statistics in Table 1 indicated a positive association between walking and health before adjusting for covariates. Model W1 examined associations between walking and health controlling for socioeconomic characteristics. All variables other than walking were measured the same as in model B1, so the magnitude and direction of association of each remained roughly the same. Walking frequency had a significantly positive association with health. For every additional walking trip made, the odds of reporting better health increased by $0.6 \%(95 \% \mathrm{CI}=[1.002,1.011])$.

Model W2 tested whether the association between walking and health was moderated by socioeconomic characteristics. The main effects of walking remained significant and increased in magnitude as trips increased. A different set of interaction variables became significant. In particular, the racial variables no longer moderated the associations between walking and health, while gender, population density, and one income category did. Women had equivalent baseline odds of reporting better health than men, but the gap increased as the number of walking trips increased. Additional transportation walking trips had greater salutary effects for men. The models indicated a positive relationship between population density and health. In a census tract of average density, the odds of reporting a higher health status remained about the same for every walking trip. But in census tracts with density one standard deviation above the mean, the odds of reporting better health increased by $0.2 \%$ for every additional walking trip, a small but statistically significant difference.

Model W3 tested whether gentrification influenced the moderation from socioeconomic status in any way. Gentrification slightly changed the results found in model W2. Walking interacted with income, employment, and age remained significant as in model W2, but interactions with gender and population density became insignificant. Gentrification status interacted with other races was marginally significant. None of the three-way interaction terms was significant. 
TABLE 3 Associations between walking for transportation and self-reported health

\begin{tabular}{|c|c|c|c|}
\hline & $\mathbf{W I}$ & W2 & W3 \\
\hline Walk trips for transp. in prev. week & $\begin{array}{c}1.006 * * \\
(1.002,1.011)\end{array}$ & $\begin{array}{c}1.024 * * \\
(1.009,1.039)\end{array}$ & $\begin{array}{c}1.017^{\wedge} \\
(0.997,1.037)\end{array}$ \\
\hline Gentrified tract & & & $\begin{array}{c}0.908 \\
(0.628,1.314)\end{array}$ \\
\hline \multicolumn{4}{|l|}{ Race } \\
\hline Black or African American & $\begin{array}{c}0.746 * * * \\
(0.636,0.873)\end{array}$ & $\begin{array}{c}0.753 * * * \\
(0.639,0.888)\end{array}$ & $\begin{array}{c}0.750 * * * \\
(0.632,0.889)\end{array}$ \\
\hline Hispanic/Latino & $\begin{array}{c}0.822 * * * \\
(0.738,0.916)\end{array}$ & $\begin{array}{c}0.823 * * \\
(0.720,0.94 I)\end{array}$ & $\begin{array}{c}0.821^{* *} \\
(0.707,0.954)\end{array}$ \\
\hline Asian & $\begin{array}{c}0.761 * * \\
(0.629,0.920)\end{array}$ & $\begin{array}{c}0.771 * \\
(0.609,0.976)\end{array}$ & $\begin{array}{c}0.787^{\wedge} \\
(0.612,1.011)\end{array}$ \\
\hline Other & $\begin{array}{c}0.704 * * * \\
(0.584,0.849)\end{array}$ & $\begin{array}{c}0.716 * * \\
(0.586,0.874)\end{array}$ & $\begin{array}{c}0.666 \text { *** } \\
(0.571,0.776)\end{array}$ \\
\hline \multicolumn{4}{|l|}{ Household income (quintiles) } \\
\hline$\$ 25,000$ to $\$ 49,999$ & $\begin{array}{c}1.445 * * * \\
(1.258,1.659)\end{array}$ & $\begin{array}{c}1.526 * * * \\
(1.312,1.775)\end{array}$ & $\begin{array}{c}1.513 * * * \\
(1.263,1.814)\end{array}$ \\
\hline$\$ 50,000$ to $\$ 74,999$ & $\begin{array}{c}1.943 * * * \\
(1.671,2.260)\end{array}$ & $\begin{array}{c}2.023 * * * \\
(1.680,2.435)\end{array}$ & $\begin{array}{c}1.990 * * * \\
(1.639,2.415)\end{array}$ \\
\hline$\$ 75,000$ to $\$ 124,999$ & $\begin{array}{c}2.268 * * * \\
(2.002,2.570)\end{array}$ & $\begin{array}{c}2.339 * * * \\
(2.027,2.698)\end{array}$ & $\begin{array}{c}2.320 * * * \\
(2.010,2.678)\end{array}$ \\
\hline$\$ 125,000$ or more & $\begin{array}{c}3.299 * * * \\
(2.928,3.717)\end{array}$ & $\begin{array}{c}3.430 * * * \\
(2.952,3.986)\end{array}$ & $\begin{array}{c}3.372 * * * \\
(2.863,3.970)\end{array}$ \\
\hline \multicolumn{4}{|l|}{ Educational attainment } \\
\hline High school & $\begin{array}{c}1.893 * * * \\
(1.689,2.121)\end{array}$ & $\begin{array}{c}1.799 * * * \\
(1.608,2.013)\end{array}$ & $\begin{array}{c}1.834 * * * \\
(1.603,2.098)\end{array}$ \\
\hline College degree & $\begin{array}{c}3.029 * * * \\
(2.657,3.453)\end{array}$ & $\begin{array}{c}2.952 * * * \\
(2.591,3.365)\end{array}$ & $\begin{array}{c}2.979 * * * \\
(2.587,3.430)\end{array}$ \\
\hline Employed & $\begin{array}{c}1.655 * * * \\
(1.520,1.802)\end{array}$ & $\begin{array}{c}1.758 * * * \\
(1.626,1.901)\end{array}$ & $\begin{array}{c}1.740 * * * \\
(1.604,1.888)\end{array}$ \\
\hline Immigrant & $\begin{array}{c}1.217 * * * \\
(1.147,1.291)\end{array}$ & $\begin{array}{c}1.221 * * * \\
(1.132,1.318)\end{array}$ & $\begin{array}{c}1.232 * * * \\
(1.150,1.320)\end{array}$ \\
\hline Female & $\begin{array}{c}0.984 \\
(0.936,1.035)\end{array}$ & $\begin{array}{c}1.026 \\
(0.980,1.073)\end{array}$ & $\begin{array}{c}1.021 \\
(0.975,1.070)\end{array}$ \\
\hline Age (std.) & $\begin{array}{c}0.527 * * * \\
(0.506,0.550)\end{array}$ & $\begin{array}{c}0.515 * * * \\
(0.496,0.536)\end{array}$ & $\begin{array}{c}0.512 * * * \\
(0.495,0.530)\end{array}$ \\
\hline Age (std.) $)^{2}$ & $\begin{array}{c}1.340 * * * \\
(1.296,1.385)\end{array}$ & $\begin{array}{c}1.374 * * * \\
(1.329,1.421)\end{array}$ & $\begin{array}{c}1.366 * * * \\
(1.313,1.422)\end{array}$ \\
\hline Population density (std.) & $\begin{array}{c}1.002 \\
(0.986,1.019)\end{array}$ & $\begin{array}{c}0.985 \\
(0.964,1.006)\end{array}$ & $\begin{array}{c}0.990 \\
(0.966,1.014)\end{array}$ \\
\hline \multicolumn{4}{|l|}{ Interactions } \\
\hline $\begin{array}{l}\text { Walking } \\
\text { Gentrification }\end{array}$ & $\begin{array}{l}\text { No } \\
\text { No }\end{array}$ & $\begin{array}{l}\text { Yes } \\
\text { No }\end{array}$ & $\begin{array}{l}\text { Yes } \\
\text { Yes }\end{array}$ \\
\hline Walk $\times \$ 25,000$ to $\$ 49,999$ & & $\begin{array}{c}0.985 * * \\
(0.976,0.994)\end{array}$ & $\begin{array}{c}0.987 * * \\
(0.979,0.995)\end{array}$ \\
\hline Walk x Employed & & $\begin{array}{c}0.985 * * * \\
(0.977,0.993)\end{array}$ & $\begin{array}{c}0.989 * * \\
(0.980,0.997)\end{array}$ \\
\hline Walk $\times$ Female & & $0.990 * *$ & 0.992 \\
\hline
\end{tabular}


share of the population, their share of trips taken, and their share of distance traveled by bicycle (Federal Highway Administration, 2017; National Highway Traffic Safety Administration, 2019; U. S. Census Bureau, 2020). Even when bicycle facilities are available, their quality or other neighborhood characteristics may yield disparate safety outcomes in communities of color (Barajas, 2018). Moreover, people of color are more likely to live near major roadways (Hajat et al., 2015) and may therefore be more exposed to air pollution and injury risks. Thus, the findings of this study could reflect that Black cyclists tend to travel under poorer environmental conditions that attenuate the potential health benefits of cycling.

In contrast, race and ethnicity did not have a moderating influence on the relationship between walking and health for any category. This was somewhat surprising given the negative experiences that people of color, and especially Black men, face in their daily interactions in public spaces, which contribute to higher stress and potentially poorer health. But it may be that because these experiences are not confined to the pedestrian environment, their effects were captured in the models by the race variables alone. Effects were different by gender, however, with women less likely to report better health as walking for transportation increased compared to men. This finding could reflect the broad experience of harassment that women face with increased exposure to walking, leading to anxiety that would negatively influence health (Davidson et al., 2016; Loukaitou-Sideris, 2016).

Third, the relationship between active travel and health did not change under conditions of gentrification. In some respects, this should not be surprising and is good news from an equity perspective. Gentrification is defined by increased public and private investment in a neighborhood. Public investment might yield additional bike lanes, improved sidewalk quality, and better streetscapes, while private investment could result in more housing and destinations that are walkable and bikeable. In theory, the benefits of such infrastructure would accrue to all neighborhood residents. However, long-time residents are often skeptical of cycling and walking improvements that might be associated with "green gentrification," causing them avoid using those modes if they do not see themselves as full participants (Harris et al., 2020; Lubitow and Miller, 2013).

On the other hand, the gentrification index we used may not reflect displacement of current residents. Gentrification and displacement are separate phenomena, the former referring to the process of influx of people and capital, the latter referring to the outflow of lower-income people and people of color (Zuk et al., 2018). The two often go hand-in-hand, so some neighborhoods we identified as gentrifying may have lost lower-income populations and populations of color and the models may have only picked up the strongest effects. Furthermore, a small share of census tracts was marked as gentrifying. This is a limitation of relying on a single definition of neighborhood change. We used a simple, though accepted, definition of gentrification that allowed us to identify census tracts nationwide but ignored local context all too necessary to understand the process by which gentrification is taking place on the ground, and its potential effects on health. Future work should use both additional quantitative and qualitative measures to measure neighborhood change.

The findings from this study yield several policy implications. Given the association between active transportation and health, planning efforts that promote cycling and walking are crucial strategies in the public health toolbox. These efforts could include a variety of policy, programmatic, environmental, and infrastructure interventions designed to encourage active transportation. However, these investments must be attentive to inequities across neighborhoods, recognizing that cycling and walking are not automatically "healthy" (or as healthy) for 
marginalized groups. For instance, our findings indicate that Black people experience smaller gains in health from cycling compared to other racial groups, potentially due to traveling in poorer environmental conditions. This suggests that planners should focus on repairing inadequate facilities and prioritizing new facilities in neighborhoods of color. Through this approach, which should be done in consultation with residents, planners can work towards not just greater health, but also greater health equity. Finally, this study did not find widespread moderating effects of gentrification on active transportation and self-reported health, although some of the associations were significant. This finding, while unexpected, is encouraging in that it suggests the health gains from active transportation might be experienced in a variety of neighborhood contexts. However, it is important to recognize that gentrification may have health impacts not measured in the current study. Thus, planners should carefully consider how support for cycling and walking investments may result in changes to health in the context of complex neighborhood change.

\section{Conclusions}

The findings in this study suggest that cycling and walking are positively associated with selfreported health, with some variations by race and SES. While cyclists in generally had higher odds of reporting excellent health, their odds of reporting better health were lower if they were Black than if they were white or in other racial and ethnic categories. Likewise, pedestrians who walked more had better health in general, but women also had lower odds of reporting better health than men per additional walking trip. There was minimal change in the relationships between active transportation and health when examining them in the context of neighborhood gentrification.

Planners and policymakers should continue to promote programs and infrastructure that support cycling and walking to improve public health, but must contend with structural inequities that may work to suppress health benefits for certain groups in the population. These efforts must work to address deficiencies first and then work with communities to equitably invest and expand opportunities for active transportation.

\section{References}

Alliance for Biking \& Walking, 2016. Bicycling \& Walking in the United States.

Andersen, L.B., Schnohr, P., Schroll, M., Hein, H.O., 2000. All-Cause Mortality Associated With Physical Activity During Leisure Time, Work, Sports, and Cycling to Work. Arch Intern Med 160, 1621. https://doi.org/10.1001/archinte.160.11.1621

August, K.J., Sorkin, D.H., 2011. Racial/Ethnic Disparities in Exercise and Dietary Behaviors of Middle-Aged and Older Adults. J GEN INTERN MED 26, 245-250. https://doi.org/10.1007/s11606-010-1514-7

Barajas, J.M., 2018. Not all crashes are created equal: Associations between the built environment and disparities in bicycle collisions. Journal of Transport and Land Use 11, 865-882. https://doi.org/10.5198/jtlu.2018.1145

Bardaka, E., Delgado, M.S., Florax, R.J.G.M., 2018. Causal identification of transit-induced gentrification and spatial spillover effects: The case of the Denver light rail. Journal of Transport Geography 71, 15-31. https://doi.org/10.1016/j.jtrangeo.2018.06.025

Bartholomew, K., Ewing, R., 2011. Hedonic Price Effects of Pedestrian- and Transit-Oriented Development. Journal of Planning Literature 26, 18-34. https://doi.org/10.1177/0885412210386540 
Benesh, S., 2015. Bicycles and Race in Portland [WWW Document]. Newgeography.com. URL http://www.newgeography.com/content/004831-bicycles-and-race-portland (accessed 2.7.20).

Bereitschaft, B., 2019. Neighborhood Walkability and Housing Affordability among U.S. Urban Areas. Urban Science 3, 11. https://doi.org/10.3390/urbansci3010011

Braun, L.M., Rodriguez, D.A., Gordon-Larsen, P., 2019. Social (in)equity in access to cycling infrastructure: Cross-sectional associations between bike lanes and area-level sociodemographic characteristics in 22 large U.S. cities. Journal of Transport Geography 80, 102544. https://doi.org/10.1016/j.jtrangeo.2019.102544

Chapple, K., Zuk, M., 2016. Forewarned: The Use of Neighborhood Early Warning Systems for Gentrification and Displacement. Cityscape 18, 109-130.

Christensen, R.H.B., 2020. Cumulative Link Models for Ordinal Regression with the R Package ordinal.

Cradock, A.L., Troped, P.J., Fields, B., Melly, S.J., Simms, S.V., Gimmler, F., Fowler, M., 2009. Factors Associated with Federal Transportation Funding for Local Pedestrian and Bicycle Programming and Facilities. J Public Health Pol 30, S38-S72. https://doi.org/10.1057/jphp.2008.60

Davidson, M.M., Butchko, M.S., Robbins, K., Sherd, L.W., Gervais, S.J., 2016. The mediating role of perceived safety on street harassment and anxiety. Psychology of Violence 6, 553-561. https://doi.org/10.1037/a0039970

Dinu, M., Pagliai, G., Macchi, C., Sofi, F., 2019. Active Commuting and Multiple Health Outcomes: A Systematic Review and Meta-Analysis. Sports Med 49, 437-452. https://doi.org/10.1007/s40279-018-1023-0

Federal Highway Administration, 2017. National Household Travel Survey.

Flanagan, E., Lachapelle, U., El-Geneidy, A., 2016. Riding tandem: Does cycling infrastructure investment mirror gentrification and privilege in Portland, OR and Chicago, IL? Research in Transportation Economics, Transportation and Land Development: A Global View 60, 14-24. https://doi.org/10.1016/j.retrec.2016.07.027

Freed, B., 2015. DC's Latest Bike Lane Fight Is Not About Bikes. Washingtonian. URL https://www.washingtonian.com/2015/10/23/dcs-latest-bike-lane-fight-is-not-aboutbikes/ (accessed 2.9.20).

Freeman, L., 2005. Displacement or Succession?: Residential Mobility in Gentrifying Neighborhoods. Urban Affairs Review 40, 463-491. https://doi.org/10.1177/1078087404273341

Golub, A., 2016. Is the Right to Bicycle a Civil Right? Synergies and Tensions Between the Transportation Justice Movement and Planning for Bicycling, in: Golub, A., Hoffmann, M., Lugo, A., Sandoval, G. (Eds.), Bicycle Justice and Urban Transformation: Biking for All? Routledge, New York, pp. 20-31.

Greenfield, J., 2012. Bike facilities don't have to be "the white lanes of gentrification." Grid Chicago. URL http://gridchicago.com/2012/bike-facilities-dont-have-to-be-the-whitelanes-of-gentrification/ (accessed 2.9.20).

Hajat, A., Hsia, C., O’Neill, M.S., 2015. Socioeconomic Disparities and Air Pollution Exposure: a Global Review. Curr Envir Health Rpt 2, 440-450. https://doi.org/10.1007/s40572-0150069-5 
Harris, B., Schmalz, D., Larson, L., Fernandez, M., 2020. Fear of the unknown: examining neighborhood stigma's effect on urban greenway use and surrounding communities. Urban Affairs Review 1078087420909529. https://doi.org/10.1177/1078087420909529

Herrington, C., Dann, R.J., 2016. Is Portland's Bicycle Success Story a Celebration of Gentrification? A Theoretical and Statistical Analysis of Bicycle Use and Demographic Change, in: Golub, A., Hoffmann, M., Lugo, A., Sandoval, G. (Eds.), Bicycle Justice and Urban Transformation: Biking for All? Routledge, New York, pp. 32-52.

Hirsch, J.A., Green, G.F., Peterson, M., Rodriguez, D.A., Gordon-Larsen, P., 2017. Neighborhood sociodemographics and change in built infrastructure. Journal of Urbanism: International Research on Placemaking and Urban Sustainability 10, 181-197. https://doi.org/10.1080/17549175.2016.1212914

Hoffmann, M.L., Lugo, A., 2014. Who is 'world class'? Transportation justice and bicycle policy. Urbanites 4, 45-61.

Immergluck, D., Balan, T., 2018. Sustainable for whom? Green urban development, environmental gentrification, and the Atlanta Beltline. Urban Geography 39, 546-562. https://doi.org/10.1080/02723638.2017.1360041

Knight, J., Weaver, R., Jones, P., 2018. Walkable and resurgent for whom? The uneven geographies of walkability in Buffalo, NY. Applied Geography 92, 1-11. https://doi.org/10.1016/j.apgeog.2018.01.008

Krizek, K.J., Johnson, P.J., 2006. Proximity to Trails and Retail: Effects on Urban Cycling and Walking. Journal of the American Planning Association 72, 33-42. https://doi.org/10.1080/01944360608976722

Landis, J.D., 2016. Tracking and Explaining Neighborhood Socioeconomic Change in U.S. Metropolitan Areas Between 1990 and 2010. Housing Policy Debate 26, 2-52. https://doi.org/10.1080/10511482.2014.993677

Li, W., Joh, K., 2017. Exploring the synergistic economic benefit of enhancing neighbourhood bikeability and public transit accessibility based on real estate sale transactions. Urban Studies 54, 3480-3499. https://doi.org/10.1177/0042098016680147

Loukaitou-Sideris, A., 2016. A gendered view of mobility and transport: next steps and future directions. Town Planning Review 87, 547-565. https://doi.org/10.3828/tpr.2016.38

Lubitow, A., Miller, T.R., 2013. Contesting Sustainability: Bikes, Race, and Politics in Portlandia. Environmental Justice 6, 121-126. https://doi.org/10.1089/env.2013.0018

Lubitow, A., Zinschlag, B., Rochester, N., 2016. Plans for pavement or for people? The politics of bike lanes on the 'Paseo Boricua' in Chicago, Illinois. Urban Studies 53, 2637-2653. https://doi.org/10.1177/0042098015592823

Matthews, C.E., Jurj, A.L., Shu, X. -o., Li, H.-L., Yang, G., Li, Q., Gao, Y.-T., Zheng, W., 2007. Influence of Exercise, Walking, Cycling, and Overall Nonexercise Physical Activity on Mortality in Chinese Women. American Journal of Epidemiology 165, 1343-1350. https://doi.org/10.1093/aje/kwm088

Mueller, N., Rojas-Rueda, D., Cole-Hunter, T., de Nazelle, A., Dons, E., Gerike, R., Gotschi, T., Int Panis, L., Kahlmeier, S., Nieuwenhuijsen, M., 2015. Health impact assessment of active transportation: A systematic review. Prev Med 76, 103-114. https://doi.org/10.1016/j.ypmed.2015.04.010

National Highway Traffic Safety Administration, 2019. Fatality Analysis Reporting System (FARS). 
Pelechrinis, K., Zacharias, C., Kokkodis, M., Lappas, T., 2017. Economic impact and policy implications from urban shared transportation: The case of Pittsburgh's shared bike system. PLoS ONE 12, e0184092. https://doi.org/10.1371/journal.pone.0184092

Pucher, J., Buehler, R., Bassett, D.R., Dannenberg, A.L., 2010a. Walking and Cycling to Health: A Comparative Analysis of City, State, and International Data. Am J Public Health 100, 1986-1992. https://doi.org/10.2105/AJPH.2009.189324

Pucher, J., Dill, J., Handy, S., 2010b. Infrastructure, programs, and policies to increase bicycling: An international review. Preventive Medicine 50, S106-S125. https://doi.org/10.1016/j.ypmed.2009.07.028

Quastel, N., Moos, M., Lynch, N., 2012. Sustainability-As-Density and the Return of the Social: The Case of Vancouver, British Columbia. Urban Geography 33, 1055-1084. https://doi.org/10.2747/0272-3638.33.7.1055

Reynolds, C.C., Harris, M.A., Teschke, K., Cripton, P.A., Winters, M., 2009. The Impact of Transportation Infrastructure on Bicycling Injuries and Crashes: A Review of the Literature. Environ Health 8, 47. https://doi.org/10.1186/1476-069X-8-47

Rojas-Rueda, D., de Nazelle, A., Andersen, Z.J., Braun-Fahrlander, C., Bruha, J., BruhovaFoltynova, H., Desqueyroux, H., Praznoczy, C., Ragettli, M.S., Tainio, M., Nieuwenhuijsen, M.J., 2016. Health Impacts of Active Transportation in Europe. PLoS One 11, e0149990. https://doi.org/10.1371/journal.pone.0149990

Saunders, L.E., Green, J.M., Petticrew, M.P., Steinbach, R., Roberts, H., 2013. What Are the Health Benefits of Active Travel? A Systematic Review of Trials and Cohort Studies. PLoS ONE 8, e69912. https://doi.org/10.1371/journal.pone.0069912

Smith, L., Stubbs, B., Hu, L., Veronese, N., Vancampfort, D., Williams, G., Vicinanza, D., Jackson, S.E., Ying, L., López-Sánchez, G.F., Yang, L., 2019. Is Active Transport and Leisure-Time Physical Activity Associated With Inflammatory Markers in US Adults? A Cross-Sectional Analyses From NHANES. Journal of Physical Activity and Health 16, 540-546. https://doi.org/10.1123/jpah.2018-0423

Smith, M., Hosking, J., Woodward, A., Witten, K., MacMillan, A., Field, A., Baas, P., Mackie, H., 2017. Systematic literature review of built environment effects on physical activity and active transport - an update and new findings on health equity. Int J Behav Nutr Phys Act 14, 158. https://doi.org/10.1186/s12966-017-0613-9

Tainio, M., de Nazelle, A.J., Gotschi, T., Kahlmeier, S., Rojas-Rueda, D., Nieuwenhuijsen, M.J., de Sa, T.H., Kelly, P., Woodcock, J., 2016. Can air pollution negate the health benefits of cycling and walking? Prev Med 87, 233-236. https://doi.org/10.1016/j.ypmed.2016.02.002

U. S. Census Bureau, 2020. American Community Survey 5-Year Estimates: 2014--2018.

U.S. Census Bureau, 2018. American Community Survey: 2014-2018 Five-Year Estimates.

U.S. Department of Transportation, Federal Highway Administration, 2017. 2017 National Household Travel Survey.

Wanner, M., Götschi, T., Martin-Diener, E., Kahlmeier, S., Martin, B.W., 2012. Active Transport, Physical Activity, and Body Weight in Adults: A Systematic Review. American Journal of Preventive Medicine 42, 493-502. https://doi.org/10.1016/j.amepre.2012.01.030

Welch, T.F., Gehrke, S.R., Wang, F., 2016. Long-term impact of network access to bike facilities and public transit stations on housing sales prices in Portland, Oregon. Journal of Transport Geography 54, 264-272. https://doi.org/10.1016/j.jtrangeo.2016.06.016 
Zuk, M., Bierbaum, A.H., Chapple, K., Gorska, K., Loukaitou-Sideris, A., 2018. Gentrification, Displacement, and the Role of Public Investment. Journal of Planning Literature 33, 3144. https://doi.org/10.1177/0885412217716439 